\title{
Representaciones del espacio urba- no y configuraciones identitarias en la literatura argentina del siglo XXI*
}

\author{
Liliana Tozzi ${ }^{1}$ \\ Universidad Nacional de Córdoba (Argentina)
}

Resumen

Las representaciones de la ciudad en la narrativa argentina de principios del siglo XXI se vinculan con las transformaciones históricas de las últimas décadas -la dictadura y posdictadura, la etapa de neoliberalismo menemista de los noventa, la crisis de 2001-2002-, que produjeron cambios profundos en el mapa político y en la cartografía social, e impactan, de maneras diversas, en la producción literaria. En este trabajo se estudian los modos en que estas transformaciones ingresan a las narrativas del período, en relación con la configuración del espacio urbano, en las novelas Puerto Apache (2002), de Juan Martini; Hijos

\section{Abstract}

The representations of the city in the Argentine narrative of the beginning of the 21st century are linked to the historical transformations of the last decades the Dictadura and the Post Dictadura, the neoliberalism stage of the 1990s, the 2001-2002 crisis-. These facts produced deep changes in the political map and in the social cartography, as well as they impact in the literary production. In this work, we study the ways in which these transformations are introduced in the narratives of the period, in relation to the representation of urban space. The corpus consist of the novels Puerto Apache (2002), by Juan Martini, Hijos

\footnotetext{
*Urban space representations and identity configurations in the Argentine literature of the 21st century

Recibido: 28 de abril de 2017 - Aprobado: 28 de octubre de 2017

Los resultados que se exponen en este artículo corresponden a la investigación desarrollada en el marco de los siguientes proyectos: "Comunidades imaginadas de fin de siglo: resignificaciones de 'nación', 'estado' y 'gobernabilidad' en la literatura latinoamericana (1995-2010)”, dirigido por la Dra. Silvia Valero (Universidad de Cartagena) y "La configuración del espacio urbano y las voces en la narrativa argentina del siglo XXI", investigación posdoctoral con Beca de la Secretaría de Ciencia y Tecnología. Universidad Nacional de Córdoba.

${ }^{1}$ Docente de la Universidad Nacional de Córdoba. Doctora en Ciencias de Lenguaje con Mención en Culturas y Literaturas Comparadas de la Universidad Nacional de Córdoba (Argentina).e-mail: tozzililiana@gmail.com
} 
nuestros (2004), de Néstor Ponce; y La Virgen Cabeza (2009), de Gabriela Cabezón Cámara.

Palabras clave: literatura argentina, ciudad, literatura y sociedad, marginalidad. nuestros (2004), by Nestor Ponce and La Virgen Cabeza (2009), by Gabriela Cabezón Cámara.

Keywords: Argentine Literature, city, literature and society, marginality.

\section{Introducción}

La narrativa argentina de principios del siglo XXI presenta una notoria diversidad en cuanto a temáticas y propuestas estéticas. Así mismo, en sus vinculaciones con la producción literaria anterior, especialmente la de fines del siglo XX. Una visión panorámica de lo producido en el terreno de la ficción y de los trabajos críticos permite establecer una serie de continuidades y líneas de fuga en el mapa literario posterior al 2000. En este sentido, la producción literaria se desplaza desde la "ciudad letrada" hacia las periferias, en un movimiento que implica no sólo dar cuenta de las transformaciones urbanas, sino también del corrimiento en el lugar del "letrado" en la trama hegemónica del poder. Si Solís, en la novela de Azuela, se ponía al lado de "los de abajo" e intentaba hablar por ellos, en la narrativa de las últimas décadas se produce una proliferación de textos donde se intenta dar la voz a los márgenes, mediante una diversidad de géneros y propuestas estéticas. La mediación que impone el procedimiento de la construcción novelesca -esa figura bajtiniana del "autor creador"- se adelgaza para dejar paso a otras voces cuyas visiones de mundo se inscriben de maneras diferentes en los textos. Entre la numerosa producción de las últimas décadas se cuentan $E l$ aire (1992), de Sergio Chejfec; La Villa (del 2001, pero fechada en 1998), de César Aira; Puerto Apache (2002), de Juan Martini; Cosa de negros (2003), de Washington Cucurto; Hijos nuestros (2004), de Néstor Ponce; La Virgen Cabeza (2009), de Gabriela Cabezón Cámara; Si mi querés, quereme transa (2010), de Cristian Alarcón; y Oscura monótona sangre (2010), de Sergio Olguín, por mencionar sólo algunas.

En este trabajo abordo la configuración del espacio urbano en las narrativas del período en las novelas Puerto Apache (2002), de Juan Martini; Hijos nuestros (2004), de Néstor Ponce; y La Virgen Cabeza (2009), de Gabriela Cabezón Cámara, en relación con las voces y las configuraciones identitarias. Sostengo que las representaciones del espacio urbano en la narrativa argentina de entre siglos incorporan la temática de la pobreza y la marginalidad a través de 
modos de representación diferentes, que tienen relación con las transformaciones sociales y culturales de la dimensión histórica. Los textos no hacen foco en "los pobres" o "la miseria" como ese constructo de lo "no narrable" que señalara en sus lúcidos ensayos Nicolás Rosa $(1997,2006)$, analizando las narrativas de la primera mitad de siglo XX. En el corpus de principios del XXI la representación de la pobreza y la marginalidad se incorpora como parte de una complejidad que refracta las transformaciones sociales de las últimas décadas, específicamente la heterogeneidad identitaria individual y colectiva.

\section{Ciudad, marginalidad y ficción}

La presencia de la marginalidad y la pobreza no es nueva en la literatura argentina, pero a lo largo del siglo XX y comienzos del XXI sus modos de representación varían. Sylvia Saítta aborda este tema en un artículo publicado en 2006, donde estudia algunas de las transformaciones que se operan desde el realismo del grupo de Boedo, hasta los nuevos modos de dar cuenta de lo social, en la década del noventa. ${ }^{2}$ De este último período, toma las novelas El aire, de Sergio Chejfec y La Villa, de César Aira, para destacar la fuga del realismo que se opera en ambos casos, como también las diferencias en los valores que cada una de las novelas pone en circulación. La autora destaca la oposición que ambos textos presentan en la representación del espacio urbano. Mientras en la novela de Chejfec la ciudad "se 'pampeaniza': deviene pampa, deviene llanura, deviene puro vacío" (99), en el texto de Aira se produce "la conversión del vacío en lleno absoluto" (100), a partir de una construcción espacial cuya saturación de elementos materiales diluye la representación realista, al tiempo que invierte el sentido fundacional de la oposición "civilización / barbarie":

De la misma manera que el desierto de Ema la cautiva (1981) revierte el vacío pampeano del lugar de la barbarie opuesto al lleno, como un lugar de hipercivilización, la villa de La Villa es también un espacio de civilización, donde perduran las reglas de solidaridad y de comunidad que el resto de la sociedad ha perdido.

En contraposición al quiebre de la idea de comunidad y la ausencia de comunicación que se opera en la novela de Chejfec, en La Villa los

${ }^{2}$ Década marcada, en Argentina, por las políticas neoliberales implementadas durante las presidencias de Carlos Menem (1989-1995; 1995-1999). 
valores de solidaridad se sostienen y fortalecen. Sin embargo, ambos textos, según la investigadora, "realizan el proyecto de la literatura social al poner en palabras un mundo casi invisible, al devolverles la voz a quienes han sido también desposeídos de ella, al narrar el mundo de la pobreza sin apelar a los facilismos del panfleto de denuncia o de la crónica periodística." (101). En los trabajos sobre la representación de la pobreza en la literatura argentina se destacan dos artículos de Nicolás Rosa $(1997 ; 2006)$ en los que se analiza este eje en la narrativa de fines del siglo XIX y comienzos del XX:

La descripción de la pobreza en el plan narrativoliterario asumió siempre una narración que apela a la cientificidad de sus enunciados (la pobreza entendida como mal social) y en el otro extremo como miserabilismo folletinesco que va desde el concepto patibulario de la niñez (que vemos en Dickens, en Emily Brontë o en escritores argentinos como el que nos sirve de guía: Elías Castelnuovo) cuyos temas se convierten en verdaderas cristalizaciones narrativas: la orfandad, la internación en celdas o asilos, y, en un espacio público, el itinerario de la pobreza como circulación en los sitios secretos de la ciudad: aquellos que marcan las entradas y salidas de la planimetría ciudadana: estaciones, vías férreas, subsuelos, subterráneos, etc. (Rosa, 1997:117).

Se distinguen así dos tipos de operaciones narrativas para el relato de la pobreza opuestas en sus intenciones: la pobreza como mal social, inserta en una lógica cientificista, por una parte; y el "miserabilismo folletinesco", por otra, cuya lógica religiosa asume su formulación más acabada en la escritura de Elías Castelnuovo (Rosa, 1997; Saítta, 2006). Desde la perspectiva de Saítta, en ambos casos se apela a una representación naturalista, en contraposición con la literatura de fines del siglo XX y comienzos del XXI, donde, si bien se observan continuidades en el eje temático de la pobreza y en la recurrencia de espacios urbanos marginales, la representación se fuga del realismo hacia otras formas compositivas que se utilizan para dar cuenta de lo social. En relación con el corpus que abordo en este trabajo, la marginalidad ingresa en el universo representado de modos diversos y heterogéneos que vuelven inoperante el concepto de "pobreza" o de "miseria", tal como se le entendía y "argumentaba" (Rosa, 1997: 127) en la narrativa de principios del siglo XX.

La literatura argentina de comienzos del XXI presenta una cartografía que mezcla y corroe las fronteras entre centro/margen, ciudad/ 
campo, barrios ricos/barrios pobres, a través de la circulación de los actores que se desplazan transversalmente por grupos diferentes desde el punto de vista de clase, género, edad, poder económico, posiciones políticas, nivel cultural, etc. Me propongo analizar un acotado corpus para estudiar algunos modos específicos de representación en los que la dimensión social ingresa a la ficción. Esto desde una perspectiva metodológica basada en el concepto de "arquitectónica" de Mijaíl Bajtín (1991):

La novela es una forma puramente compositiva de organización de las masas verbales. A través de ella se realiza en el objeto estético la forma arquitectónica de acabamiento artístico de un acontecimiento histórico o social, constituyendo una variante de la culminación ética. [...] cada forma arquitectónica se realiza a través de ciertos procedimientos compositivos (25).

En los textos del corpus, la ciudad y sus márgenes avanzan sobre el centro, diseñando una geografía que da cuenta de la movilidad social, económica y cultural, y de los diferentes modos en que la ficción refracta esas transformaciones. En el conjunto de la producción de entre siglos, Puerto Apache se inscribe en la línea de las novelas de Chejfec y Aira estudiadas por Saítta, mediante una escritura que, apartándose de los procedimientos convencionales del realismo, incorpora la dimensión social y sus transformaciones en el discurso literario. En la novela de Martini, la complejidad de una cartografía dinámica se inserta en la ficción a través de un escenario que desplaza, borra y rediseña permanentemente las fronteras, y de una polifonía que da cuenta de la heterogeneidad de lo social. En ese intento de incorporar nuevas voces sociales a la ficción, Puerto Apache apela a la voz de la Rata, un "villero ilustrado", cuyo registro irrumpe desde las primeras líneas instaurando un verosímil que se sostiene a lo largo de toda la novela. El tono y la vocalización del personaje, leídos en clave bajtiniana, entraman la arquitectónica novelesca.

Las novelas de Néstor Ponce y de Gabriela Cabezón Cámara, por su parte, organizan universos narrativos que, a través de apuestas estéticas diferentes, no sólo apelan a la heterogeneidad de los márgenes, sino también a un reposicionamiento de la figura del letrado. En ambas novelas, los personajes narradores, que se acercan a los asentamientos marginales para describir ese mundo otro a través de la crónica periodística, sufren un proceso de transformación que desestabiliza su esquema de valores y deconstruye los cimientos de su propia configuración identitaria. Retomo la contraposición que Saítta destaca entre Chefjec y Aira, entre una ciudad que se 
"pampeaniza", al vaciarse progresivamente, invadida por el campo, y el lleno absoluto aireano que opera por saturación, en relación con Puerto Apache.

En la novela de Martini, el asentamiento que se crea en el espacio natural de la Reserva Ecológica de Buenos Aires se ubicaría en un espacio fronterizo, puesto que, si bien ocupa (okupa) el espacio, lo "urbaniza" y conforma una comunidad cuyos valores de solidaridad recuerdan la villa aireana, el intento fracasa al ser sus dirigentes desplazados y reemplazados por emisarios del poder político y económico. Así, el gesto "civilizador" se invierte. En la novela de Cabezón Cámara, por otra parte, la saturación sostiene el andamiaje escriturario mediante una estética neobarrosa ${ }^{3}$ que hace del exceso y la heterogeneidad su punto de anclaje composicional y lingüístico. También Hijos nuestros se impregna de esta especie de voluntad de convertir lo vacío en lleno que Saítta destaca en la narrativa de Aira. La novela de Ponce, sin embargo, construye ámbitos cerrados que instauran una atmósfera de encierro y opresión.

En las tres obras sobresale la impronta procesual y dinámica de las configuraciones identitarias, que recorren transversalmente diversos grupos etarios, económicos y culturales. En este sentido, las relaciones entre identidad y territorio que se imprimen en el ensayo de interpretación de la primera mitad del siglo XX, con Ezequiel Martínez Estrada o Bernardo Canal Feijóo, adoptan nuevas formulaciones a la luz de interpretaciones de las últimas décadas. Tomando específicamente el espacio rioplatense representado en las novelas, la ciudad y sus modos de leerla se reconfiguran. En este sentido, el concepto de "ciudad letrada" de Ángel Rama, extensa e intensamente analizado por la crítica académica, resulta rentable para el análisis. De todos modos, no es el objetivo de este trabajo pasar revista al amplio estado de la cuestión sobre la categoría del crítico uruguayo, sino tomar algunos elementos en relación con la problemática planteada. A continuación, abordaré los textos del corpus con el propósito de analizar los modos en que la ficción da cuenta de las transformaciones sociales y las configuraciones identitarias a través de las voces y los espacios urbanos representados.

\footnotetext{
${ }^{3}$ Consideramos el "neobarroso" desde la perspectiva de Néstor Perlongher (2008): "Producto de cierto despedazamiento del realismo, paralelo al desgaste del 'realismo mágico' y de lo 'real maravilloso', la eclosión de una variedad de escrituras instrumentales más o menos transparentes dispersa en el desierto los aduares de los estilos cristalinos" (99).
} 


\section{Sujetos fronterizos: Puerto Apache y los "problemas del siglo XXI"}

El narrador protagonista de Puerto Apache es Pablo Pérez, "la Rata", habitante de Puerto Apache, un asentamiento ubicado en la Reserva Ecológica, frente a Puerto Madero, en la ciudad de Buenos Aires. El nombre del lugar combina el de Puerto Madero un sector de la Ciudad Autónoma de Buenos Aires para habitantes con alto poder adquisitivo- con el de Fuerte Apache -una de las villas del Gran Buenos Aires-. Así, fusiona los "dos mundos" que se mencionan en la novela: por una parte, el ámbito del poder político y económico, donde la fachada de shoppings, dúplex y restaurantes encubre la corrupción y los negocios turbios. Por otra parte, el de los grupos sociales que sufren la marginación creciente de un sistema que los excluye -un conjunto heterogéneo conformado por vendedores de drogas, prostitutas, inmigrantes ilegales, cartoneros y ex trabajadores que quedaron fuera del sistema laboral, como consecuencia de las políticas económicas implementadas en las últimas décadas.

La Rata tiene 29 años, vive con Jenifer, la madre de sus dos hijos, y trabaja como traficante ("correo") del Pájaro, un empresario gastronómico que encubre con esta actividad el negocio de venta de drogas. Está enamorado de Maru, la mujer del Pájaro, y se ve envuelto en un robo entre distintas facciones de la banda, como consecuencia de lo cual es secuestrado y golpeado. Luego de escapar, intenta averiguar la verdad, pero ese descubrimiento implica el encuentro con varios muertos y el dolor de saber que Maru ha sido uno de los cerebros del plan.

Otro de los ejes de la trama lo constituyen los intentos, por parte de sectores empresarios y políticos, de erradicar el asentamiento para emprendimientos inmobiliarios que funciona, en muchos casos, como lavado del dinero de los grandes negocios de la corrupción política y económica. Los intereses que se ponen en juego, así como las prácticas de la violencia y la represión, reorganizan en la ficción la trama de la realidad política del país: grupos armados ingresan al asentamiento, incendian viviendas y golpean a sus habitantes. Como consecuencia del ataque, el padre de la Rata muere y los pactos por la sucesión en el gobierno de Puerto Apache transforman la naturaleza del proyecto original, al adoptar elementos del mismo modelo que se rechazaba.

\footnotetext{
${ }^{4}$ En adelante, se utiliza la sigla PA para referirse a la novela y se reserva la denominación "Puerto Apache" para el asentamiento creado por la ficción.
} 
Si bien algunos ejes recuperan líneas de sentido trabajadas en otras obras del autor -las luchas por la sucesión, el abuso de poder por parte de los sectores políticos y económicos dominantes-, con este texto la narrativa de Martini da un giro respecto de su poética anterior, a través de una representación de la ciudad y del diseño de personajes sobre el referente de la realidad social de principios del nuevo siglo. Al respecto, en una entrevista el autor reconoce:

[...] esta irrupción furiosa de la crisis en la realidad argentina, y esta caída de la política en la que todavía estamos metidos y que nos va arrastrar, yo creo, en su vértigo, salvo que nos decidamos verdaderamente a refundar este país en otros códigos, se hizo tan imperativa y asaltó tantas cosas, entró por asalto en tantos lugares, que entró por asalto en mi escritura. Entonces interrumpí Colonia y escribí Puerto Apache que tiene un referente inmediato muy fuerte. (Araujo, año: 17).

El "asalto" de la realidad en la escritura lo da la voz narrativa: la de un villero cuya mirada muestra la ciudad en su costado periférico, en los desechos materiales y humanos. A través del sobrenombre, el protagonista reafirma su identidad marginal: "Yo soy la Rata", repite a lo largo del relato: "[...] yo soy una rata de cuarta. Yo vivo en las cloacas, morfo basura, salgo a la calle a buscar roña, ¿entendés Máquina? Las ratas nos salvamos con la roña." (10). La "roña" y la "basura", los restos en estado de putrefacción, se convierten en materia para la construcción de la historia. El personaje fluctúa entre diferentes mundos. Es, en palabras de Marcelo Cohen (2003), "un desplazado crónico". ${ }^{5}$ El discurso desde ese lugar fronterizo implica la posibilidad de intervenir para impactar en el Otro, de insertarse en la trama del discurso social para inscribir un discurso alternativo.

Por otra parte, el cronotopo de la ciudad de Buenos Aires organiza una cartografía detallada, con calles y barrios donde se destaca Puerto Apache en contraposición con Puerto Madero, a través de un juego

\footnotetext{
${ }^{5} \mathrm{Al}$ respecto, el crítico afirma: "Puerto Apache absorbe el tipo literario del investigador melancólico en la voz peculiar de la Rata, un desplazado crónico. [...] La Rata es, desde luego, un ideal (como lo es ese asentamiento lumpen junto a Puerto Madero); sólo se cumple en su voz: un híbrido de diversos argots y de resabios del demorado, poliédrico estilo objetivo de otros libros de Martini. Sin embargo, ese delicado artificio lo aparta del mito y a la vez de la abyección, lo que ya es un atisbo de salida. Martini no saca al Rata de la intemperie, lo que sería una falacia, pero lo alza un poco por encima del barro, 'tira hacia arriba', como si supiera que es imposible un acuerdo justo entre dos culturas cuando el arte de masas no es Discépolo sino Gilda (cuyas canciones pueblan Puerto Apache)" (Cohen, 2003: 4).
} 
de espejos que marca la oposición, pero también la continuidad entre ambos espacios. En efecto, la mirada de la Rata se proyecta desde uno de estos espacios hacia el otro, alternadamente: "Yo veo, de vez en cuando, desde Puerto Apache, las luces de los docks enfrente del Dique 4" (25); "Entre un par de edificios en construcción, del otro lado del Dique 4, más allá de Puerto Madero, se ven los árboles de la Reserva [...] me pregunto si yo tengo que estar acá o tengo que estar allá." (65). Los deícticos refuerzan la relación: "allá" y "acá" invierten su significado según la posición del enunciador y refuerzan la posición transitoria de la Rata.

Adrián Gorelik (2004) analiza las transformaciones urbanas en la ciudad de los noventa considerando el "giro epocal" como producto de la acumulación de tres tipos de cambios: a) la "urbanización" del capitalismo; b) la crisis del espacio público; y c) la autonomía de la ex capital. La urbanización del capital privado implica "la conversión en negocio de fragmentos completos de ciudad o grandes extensiones territoriales no como asiento neutro de inversiones, sino en tanto ciudad y en tanto territorio" (210). Por otra parte, la crisis del espacio público tensiona un supuesto carácter urbano tradicional-moderno con la novedad de la modernización global:

Aquella ciudad moderna se produjo desde el centro hacia la periferia, mostrando a medida que se alejaba sus pústulas, sus incapacidades, sus omisiones. Esta ciudad de la modernización se está produciendo en sentido inverso: precisamente desde la periferia, desde los puntos más débiles del sistema anterior, hacia el centro; lo que en el sistema anterior era una falla se convierte en el nuevo núcleo de sentido (217).

En relación con ello, las calles y barrios de Buenos Aires se encuentran intervenidos por el margen: Lavalle es "un valle de lágrimas" (71); el Cementerio de la Recoleta funciona como centro de intercambio de favores sexuales a bajo precio. En los cines de Belgrano el sobrino de la Mona Lisa maneja un grupo de chicos que ofrece sexo rápido en los baños. Los hoteles de baja categoría, como la pensión de Plaza Italia, donde vive el Ombú y el hotel de Paseo Colón, donde la Rata pasa la noche, perseguido por los ayudantes del Pájaro, se contraponen a los hoteles de lujo, como el Alvear, el casino y el barrio Las Cañitas, donde circulan los nuevos ricos que produce el sistema: narcotraficantes, barras bravas devenidos en empresarios, mafiosos que ascienden en el ámbito político, marginales que intentan "saltar" al centro sin poder integrarse del todo. Así, la representación de la ciudad incorpora, a través de la mirada de la Rata, una visión de 
la decadencia urbana que se materializa en la acumulación de los desechos materiales y sociales. El detritus en PA es el margen que segrega un centro identificable como el poder hegemónico en tiempos de la globalización. Integrantes de las clases medias, como el caso de Garmendia, pasan a la villa al perder trabajo y vivienda; los inmigrantes de países europeos periféricos que el centro desecha y son destinados al Tercer Mundo. La representación de los desechos es bien diferente de la que opera en novelas de principios del siglo XX, como Las colinas del hambre, de Rosa Wernicke, donde "la montaña de basura era la emergencia de los restos del festín ciudadano": "En la disolución de los espacios se genera un interespacio funesto donde transita el hambre" (Rosa 1997: 118). Los pobres en ese corpus constituyen un grupo fuera del espacio y fuera del tiempo, "sujetos in-habitados de la Historia" (119) que protagonizan un relato de la miseria, única forma posible de narrar la pobreza. En PA, la "mugre" y la "roña" no son privativas de los villeros, sino que invaden también el centro con personajes como el Pájaro o Maru, que intentan ingresar a ese "otro mundo" de lujo, dólares y viajes a Miami. El Primer Mundo contiene la corrupción y la basura como un quiste que hace metástasis en el centro.

La organización social de Puerto Apache se establece sobre la base de algunos puntos de anclaje: un orden que se evidencia en la distribución del espacio urbano; la resemantización del concepto de legalidad, que invierte los términos del discurso hegemónico; y el rescate de valores en los vínculos interpersonales, como la solidaridad y la amistad. La conjunción de los elementos señalados opera como base para la construcción identitaria colectiva, que se condensa en el enunciado escrito en el cartel de entrada a Puerto Apache: "Somos un problema del siglo XXI". El significado apunta al carácter conflictivo de estos grupos cuya ubicación en la estructura social no tiene límites definidos. Los personajes que habitan Puerto Apache representan actores sociales que se encuentran en una zona fronteriza y móvil; su dinámica impide incluso el confinamiento que la lógica globalizada impone a los excluidos del sistema, de allí su carácter "problemático". Según apunta María del Carmen Feijoó (2003), como resultado global de las transformaciones en la movilidad social, los cambios tecnológicos y los consecuentes procesos de reestructuración del mercado laboral, se produce la caída de dos principios organizadores de la vida popular: la homogeneidad de los barrios y el principio de heterogeneidad inter barrial. Como consecuencia de ello, la "angustia de definir quién soy yo surge, en buena medida, de adicionar la pérdida de la identidad laboral a la de la identidad barrial" (82). En este sentido, la comunidad de Puerto Apache representa un intento superador de esta problemática, a 
partir de un proyecto que incorpora un nuevo concepto de legalidad y un nuevo orden institucional y social de integración colectiva.

Los habitantes de Puerto Apache, si bien producen un discurso alternativo, finalmente resultan absorbidos por la lógica del sistema. Sin embargo, algunos puntos de anclaje se sostienen: los valores de la amistad y la solidaridad en los vínculos interpersonales y la función de la narración para construir un relato propio. El final de la novela plantea una apertura significativa que inscribe la necesidad de una transformación y un cuestionamiento sobre el futuro.

\section{El grito en la noche: Hijos nuestros, de Néstor Ponce}

La novela de Néstor Ponce presenta procedimientos de montaje que adquieren particular relevancia en torno a las voces narradoras. En efecto, además del narrador principal, Juan Carlos Rébora, se incorpora la presencia de un editor -el periodista Sadim, colega a quien Rébora corrige y "forma" en la redacción periodística- que escribe un "Glosario" del final y cuestiona el relato del narrador. Las voces se alternan a través de un procedimiento de montaje que incorpora fragmentos de grabaciones testimoniales. Por otra parte, a lo largo del proceso para "recoger datos", el narrador se desplaza desde el lugar de observador hacia un posicionamiento que lo incorpora -al menos parcialmente- al grupo observado.

Así, los relatos del Bocha, de su padre Bonanza y de su amigo Careca, presentan una serie de acontecimientos que hilvanan el relato fundacional del asentamiento con la vida cotidiana de la familia y las aventuras de la banda que forman los jóvenes con una narración que inscribe entre sus pliegues las transformaciones sociales y políticas del contexto histórico. Rébora escribe, según explicita reiteradamente en el texto, "para entender". El relato surge de un impulso anclado en la experiencia subjetiva, según se explica desde el comienzo: "De alguna manera tengo que encontrarle nombre a esto, a esta pesadilla de culebra negra, por darle un nombre [...]" (1). Este disparador, que fusiona lo emocional con lo intelectual, reelabora en la ficción una diversidad de procedimientos de investigación sociológica: el método etnográfico, el estudio de caso, la observación participante, el registro y la transcripción de los testimonios. En relación con ello, la intención del trabajo narrativo reside en un impulso por desplazarse desde esa mirada antropológica hacia un lugar profundamente subjetivo, que instala la necesidad de comprender el lugar del otro para comprenderse y construirse a sí mismo. Y esto no sólo imprime al texto su calidad literaria, sino que 
instaura la ficción como un modo de conocimiento alternativo, que pone en evidencia las transformaciones sociales, el corrimiento de las fronteras culturales y la configuración de nuevas identidades al margen de los límites que traza la hegemonía.

La trama urbana de la villa, formada por callejones y pasadizos, construye una especie de laberinto, una "jaula", como las habitaciones donde duerme la familia del Bocha -núcleo constituido por el padre, Bonanza, que caza diversos animales para venderlos los fines de semana en la feria de la ruta que va al río; la Moni, hermanastra menor del Bocha; y este, a través de quien el narrador logra ingresar al asentamiento-. "Mi casa parece un zoológico", advierte el Bocha (17), e instala así una analogía entre los animales cazados por su padre y ellos mismos, en la jaula de su habitación, que a su vez se inserta en la jaula de la villa. Un tejido urbano caótico y fragmentado complejiza el sentido del orden simbólico y la idea de comunidad ya no responde a un orden impuesto desde la ciudad letrada dominante en el siglo anterior, sino que se construye a partir de una dinámica siempre en proceso, siempre inestable. La "ciudad real" incorpora la periferia como parte constitutiva de una cartografía fragmentada y heterogénea donde las fronteras se desplazan, se borran y se instauran nuevas delimitaciones. Gorelik afirma:

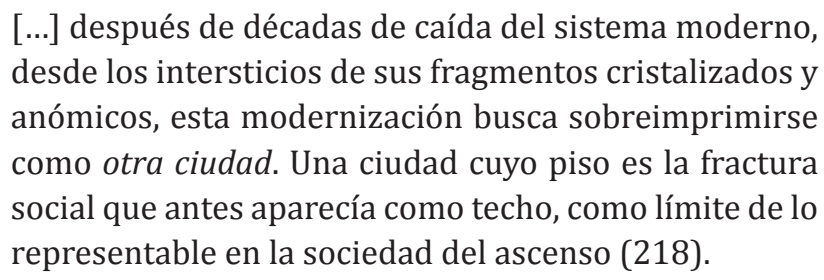

Fractura social que pone en circulación una multiplicidad de actores que se deslizan transversalmente a través de las zonas de este nuevo mapa social y cultural. Los personajes de Hijos nuestros forman una banda en una de las villas bonaerenses que incursiona en robos, secuestros e incluso en el asesinato. El relato entrecruza las barras bravas futboleras con el delito y la represión policial, los bailes de cuarteto con la música rockera de los setenta, la villa con Puerto Madero, las vías del ferrocarril con las autopistas, Buenos Aires con Brasil. En este marco, la idea de pertenencia social se organiza por oposición a una diversidad de otros: las "fuerzas del orden", los habitantes de Puerto Madero, pero también respecto de otros grupos que habitan sus mismos territorios, como los "bolitas" o los "paraguas" (35) -apelativos despectivos para aludir a los inmigrantes bolivianos y paraguayos, respectivamente-. El relato marca así una construcción identitaria que da cuenta de líneas de pertenencia y de 
diferenciación respecto de los otros que, en términos de Stuart Hall (2003), promueven interpelaciones y contribuyen a la dinámica de los procesos de identificación. ${ }^{6}$

Por otra parte, las fronteras también se desplazan y se reformulan a través del cuestionamiento de los límites respecto del género sexual y de los géneros literarios. Así, el narrador y Lorenzo forman una pareja no sólo amorosa, sino también literaria, puesto que Lorenzo representa una especie de alter ego del narrador, que cuestiona los procesos de elaboración y las elecciones estéticas del texto: "Loren me critica asestándome los diez mandamientos y una tirada de huevos: uno) lo que estás escribiendo es un desbole total, raja para todos lados, son filones de historias parciales; dos) no tengo ni idea de cómo son los personajes" (42).

El narrador, por su parte, insiste en que escribe "para entender", y vuelve una y otra vez sobre los hechos, los escribe y reescribe mediando entre las voces grabadas y la pantalla de la computadora. Este proceso puede representarse con la figura de la espiral, un círculo que vuelve sobre sí, pero nunca al mismo sitio, sino que se "enrosca" -verbo que se reitera a lo largo del texto- sobre sí mismo. La escritura apela a este procedimiento que aparece aludido de diversas maneras en el texto, desde las culebras que atrapa y vende Bonanza a "la pesadilla de culebra negra", a la que alude reiteradamente el narrador, como constitutiva de la historia que se cuenta; desde las cintas de los casetes donde se graban las entrevistas, que Rébora desarma y vuelve a enroscar, hasta las palabras que se entraman y rebobinan en el relato. Así mismo, en los vínculos parentales que entrelazan las relaciones entre padres e hijos y abren la multiplicidad de sentidos del título. En relación con ello, la expresión "hijos nuestros" recupera el significado del discurso "futbolero" de "tener de hijos" aplicado a los rivales por el equipo vencedor: "son hijos nuestros" implica que el "nosotros" se ubica en un plano de superioridad en la cancha. En el texto, sin embargo, el significado se proyecta a un colectivo que excede el plano de la puja deportiva: “-Nos llamamos 'Hijos Nuestros'. Somos 'Hijos Nuestros'./ A mí me gustó enseguida. 'Hijos Nuestros', sonaba lindo,

\footnotetext{
6 "Uso 'identidad' para referirme al punto de encuentro, el punto de sutura entre, por un lado, los discursos y prácticas que intentan 'interpelarnos', hablarnos o ponernos en nuestro lugar como sujetos sociales de discursos particulares y, por otro, los procesos que producen subjetividades que nos construyen como sujetos susceptibles de 'decirse'. De tal modo, las identidades son puntos de adhesión temporaria a las posiciones subjetivas que nos construyen las prácticas discursivas (véase Hall, 1995). Son el resultado de una articulación o 'encadenamiento' exitoso del sujeto en el flujo del discurso, lo que Stephen Heath llamó 'una intersección' en su artículo pionero 'Suture'” (Hall, 2003, 20).
} 
el canario cantaba y la cerveza estaba fresquita./ -¿Saben por qué? / Fresquita la cerveza. Estábamos saliendo de perdedores. Por fin./ Porque somos los padres de los hijos de puta." (80). La construcción del "nosotros" se opera a partir de un proceso de identificación en oposición a los "otros", que incluyen a los "bolitas" y los "paraguas", pero también a la fuerza policial y a los habitantes del otro lado de la autopista.

De este modo, la escritura se desliza, va y vuelve. Patina como la Moni en el barro de la villa y se enrosca, como las culebras de Bonanza; como las cintas de los casetes en el cuerpo de Rébora, mientras las destruye para reconstruirlas en el relato. Al modo de una espiral que va y vuelve entre el pasado y el presente, entre las calles de la villa, los edificios de puerto Madero, el departamento oscuro y decadente de Rébora y la redacción del periódico, la narración avanza tratando de entender/entenderse. La función política se imprime así en el intento del enunciador de pensarse como parte de una construcción en la que está, al mismo tiempo, afuera y adentro; de esos "hijos nuestros" que son, al mismo tiempo, eslabón en la genealogía e "hijos de puta"; que son los "otros" y una parte del "nosotros". El texto organiza un relato fragmentado y crispado, que se quiebra con ese grito que resuena, repetido, en medio de la noche, y que se reitera en el final de la novela: "es un grito de otros que pasa por mi voz, que sale y que corre, que corre y que sale, por fin, por fin. Grito, gritamos todos en la ciudad y yo estoy llorando" (85).

\section{Polifonía y construcciones de la historia: La Virgen Cabeza, de Gabriela Cabezón Cámara}

Las acciones narradas en La Virgen Cabeza se desarrollan en El Poso, una villa ubicada en San Isidro, en la provincia de Buenos Aires. Allí llega Qüity para escribir una crónica periodística sobre la "Hermana Cleopatra", una travesti que habla con la Virgen y organiza a la gente para sacar a los chicos de la calle y de la droga. El mundo narrado incluye prostitutas, travestis, proxenetas, ladrones, narcos, jefes de seguridad, policías corruptos y arrepentidos, poniendo en escena la heterogeneidad de una cartografía atravesada por diversos estratos sociales, culturales, económicos y de género -sexual y discursivo. En la novela, poderosos grupos de empresarios intentan obtener los terrenos de la villa para desarrollar megaproyectos inmobiliarios, y ante la resistencia de los habitantes, la represión policial arrasa con viviendas y vidas humanas. El quiebre que se produce en los personajes de Cleo y Qüity, luego de enfrentarse con la muerte de su gente, coincide con el comienzo de la historia de amor entre ellas. 
Amenazadas por su posición en la villa erradicada, huyen, primero a una isla en el Delta del Paraná, y luego, a Miami, donde nace María Cleopatra, hija de ambas. Allí obtienen fama y dinero gracias a la "cumbia de la Virgen Cabeza", con letra de Qüity, y a la prédica religiosa de Cleopatra. Finalmente, según se cuenta en el "Epílogo" de la novela, Cleo deja a Qüity y a su hija para ir a predicar a Cuba, por mandato de la Virgen, con una gigantesca imagen construida con piedras preciosas, que costó la mayor parte de la fortuna que habían obtenido.

La villa El Poso de la ficción reconstruye la realidad de los asentamientos marginales ${ }^{7}$, con la desprotección, el despojo y la violencia que sufre una población excluida de la seguridad y el bienestar que debería proveer el Estado. No es casual el nombre del asentamiento de la ficción: "El Poso", con "s", lo que agrega un plus de significación por el juego léxico entre poso y pozo. Más allá del efecto humorístico que abre la posibilidad de un error ortográfico, el término se resemantiza con la significación de ambos términos: la geografía del lugar remite a la zona "del bajo", al "pozo" donde se acumula el agua durante las lluvias y también donde suelen ubicarse los barrios marginales en los conglomerados urbanos. El término, sin embargo, también se refiere al sedimento que queda en el fondo, el resto desechable, el poso. La villa se ubica en la parte baja de la zona y remite a las capas ubicadas en la parte inferior del estamento social.

El discurso literario pone el acento en lo escatológico: el resto que se deposita en el poso reúne el excremento, el vómito, el semen, en situaciones que se describen con minuciosidad en un relato donde todo resulta exacerbado, con ecos del neobarroso rioplatense: "Éramos una villa ecológica, reciclábamos casi todo, hasta la misma mierda que se comían las ratas reales, las fiesteras after hour, las coprófagas" (107). Las carpas, peces que se destacan por su capacidad de supervivencia en un medio adverso, pasan a integrar ese mundo marginal como un elemento que asegura la supervivencia. Al igual que los habitantes de la villa, pueden alimentarse de los restos de otros, organizando una cadena ecológica del desecho constituida por eslabones que avanzan progresivamente hacia niveles de mayor marginalidad.

\footnotetext{
${ }^{7}$ La situación que se narra en La Virgen Cabeza reproduce hechos que suceden en la dimensión histórico- social, algunos de los cuales -muy pocos lamentablementesuelen aparecer en la crónica periodística. Como ejemplo, podemos citar: "Incumplimiento del plan de viviendas La Cava" (Sobre la ejecución de plan de viviendas en La Cava, 2007).
} 
El simbolismo del agua adquiere en la novela múltiples sentidos. Por una parte, se une a la putrefacción, al barro, a los desechos sociales de un sistema de exclusión que expulsa al pozo/poso ubicado detrás del cartel de publicidad que separa el asentamiento "del otro mundo". Por otra parte, la construcción del estanque para la cría de carpas opera como punto de anclaje para la transformación en una comunidad más unida con objetivos comunes. Las modificaciones en la disposición urbana traducen una planificación que persigue determinadas metas, pone en relación el orden de los signos con el de la cartografía, y en este punto resulta inevitable la relación con la conceptualización de Ángel Rama en La ciudad letrada ([1984] 2004). ${ }^{8}$

El trazado urbano caótico de la villa no responde a la lógica hegemónica de la razón instrumental, sino a una visión de mundo que se organiza en el borde del sistema. Sin embargo, ese caos da cuenta de un ordenamiento propio, coherente con una manera de plasmar en el territorio una visión cultural alternativa, donde la "cabeza" que organiza el plano responde a otra lógica y piensa otro concepto de comunidad, fuera de la idea de Estado y de Nación. La configuración cronotópica de la villa incorpora los valores de un grupo social fuera de lugar, que, al ser despojado del territorio propio, se traslada a Miami, donde establece una micro comunidad en otro espacio físico, tan ajeno y hostil como puede serlo el "más allá del muro" de la villa El Poso de Buenos Aires.

La valoración que subyace en las acciones de despojo y violencia es la deslegitimación de los villeros como parte integrante de una comunidad más amplia: los borran de su espacio, de su tiempo y de sus valores culturales. En consecuencia, también del relato de la Historia, puesto que en la villa todo es desechable y perecedero, e incluso los restos se consumen a tal punto que ni siquiera permanecen como materialización de la Historia. Como expresa el final del poema que escribe Qüity cuando muere el Torito, un personaje de la villa que las acompaña en el exilio en Miami: "Aunque atemos a la suerte,/ No nos salva ni el destierro,/ es super fast nuestra muerte:/ nadie llega a los cincuenta/ siempre hay bala o puñalada/ transformándonos en tierra,/ humo, polvo, sombra, nada." (104) ${ }^{9}$.

\footnotetext{
${ }^{8}$ Resulta relevante, respecto del concepto de Rama, el debate planteado, entre otros intelectuales, por Jean Franco (2002) y Josefina Ludmer (2010).

${ }^{9}$ La escritura de Gabriela Cabezón Cámara incorpora la intertextualidad de diversos modos, tanto de la cultura hegemónica (como el intertexto del soneto de Góngora presente en el fragmento citado) como de múltiples manifestaciones de la cultura popular.
} 
La falta de trascendencia en la Historia se liga a la perspectiva religiosa mediante una ritualística pagana que encarna en la figura de la Virgen Cabeza y que combina elementos del santoral católico con los dioses del Olimpo, heterogeneidad que desarticula la organización canónica de los saberes desde la cultura hegemónica. Ante el relato de Cleo sobre sus diálogos con la Virgen, Qüity se interroga: “[...]¿cómo podía citar la Odisea casi letra por letra? No podía haberla leído en su pobre puta vida. ¿De dónde mierda sacaba cosas como esa? ¿Existirá la Virgen y le dará por los clásicos y las putas pobres?” (17). El culto a la Virgen, comparable con la santificación que hace la cultura popular de personajes que la representan, como el Gauchito Gil, la Difunta Correa, los cantantes Gilda y Rodrigo, o personajes del entorno que son elevados a la categoría de santos milagrosos, como el Frente Vital, protagonista de la non fiction novel de Cristian Alarcón Cuando me muera quiero que me toquen cumbia (2003), recupera el sentido religioso como práctica comunitaria que refuerza el sentido de pertenencia y la resistencia contra un entorno que los excluye: "Después entendí; no los escucharía ningún dios, pero se escuchaban ellos todos juntos y esa unión era fuerza, y eso de que 'los hermanos sean unidos porque esa es la ley primera' en la Argentina lo saben hasta los analfabetos" (60).

La alternancia de las voces narradoras de Quity -la voz letrada-y Cleopatra -mediadora entre la voz de la Virgen Cabeza y el poblado villero- pone en contacto dos cosmovisiones que convergen en el amor y en la maternidad, así como en la voluntad de construir un relato y publicarlo en forma de libro para dejar testimonio de los hechos: inscribir la historia de la comunidad en la Historia colectiva.

\section{Para concluir}

El recorrido de las líneas de investigación en el corpus que se analiza pone de manifiesto continuidades y discontinuidades en directa vinculación con el contexto histórico-social. En la narrativa de comienzos del nuevo milenio la urbe y sus periferias ocupan un lugar central, poniendo en primer plano voces y subjetividades cuya marginalidad atraviesa diversas capas sociales, etarias, económicas y culturales. La ciudad se desordena. El orden de los signos, que, según destaca Rama, determinaba la organización del diseño urbano a partir de una idea de Estado que distribuía en el mapa urbano los modos de ejercicio y circulación del poder, cede paso a un orden caótico que invierte el proceso. La cartografía urbana se rediseña permanentemente, según un orden no necesariamente planificado, 
sino surgido espontáneamente, regido por las necesidades o las urgencias de grupos sociales que ocupan el espacio y promueven nuevos ordenamientos sociales, culturales y económicos.

Las fronteras no delimitan territorios separados, sino que diseñan un entramado complejo, donde se entrecruzan múltiples variables y se pone de manifiesto la dinámica de la cartografía social. Géneros discursivos y sexuales, búsquedas estéticas y mediaciones narrativas dan cuenta de una polifonía que intenta incorporar al discurso literario la conflictividad del discurso social. Los textos analizados revelan la variedad de la producción literaria argentina de las últimas décadas y la diferencia en los modos de incorporación de los procesos de marginalización a la narración literaria. Los autores analizados constituyen sólo una muestra reducida, a la cual pueden agregarse muchos otros, como Oliverio Coelho, Hernán Ronsino, Leila Guerriero, María Sonia Cristoff, Fernando Murat, Estela Smania, María Teresa Andruetto, por mencionar sólo algunos ejemplos. La heterogeneidad de las propuestas estéticas da cuenta de la dinámica diversa de lo social, pero también de valorizaciones diferentes sobre las configuraciones identitarias individuales y colectivas. Las propuestas fugan de concepciones esencialistas mediente un extenso arco que plantea múltiples modos de ser, estar y devenir en el universo globalizado del tercer milenio.

\section{Bibliografía}

Araujo, L. (2003). "Entrevista a Juan Martini”, Revista Hispamérica, no 94, Maryland, USA, pp. 33-48.

Bajtín, M. [1975] (1991). Teoría y estética de la novela. 1975. Madrid: Taurus. [1982]. (1998). Estética de la creación verbal. México-Madrid: Siglo Veintiuno Editores.

Cabezón Cámara, G. (2009). La Virgen Cabeza. Buenos Aires: Eterna Cadencia.

Cohen, M. (2003). "Ciudad indecente”, Revista milpalabras, no 5 (Marzo), Buenos Aires, pp. 11-15.

Feijoó, M. (2003). Nuevo país, nueva pobreza. Buenos Aires: Fondo de Cultura Económica.

Franco, J. (2002). The Decline and Fall of the lettered City. Latin America in the Cold War. Cambridge: Mass; London: Harvard University Press.

Gorelik, A. (2004). Miradas sobre Buenos Aires. Historia cultural y crítica urbana. Buenos Aires: Siglo Veintiuno Editores.

Hall, S. (2003). "Introducción: ¿quién necesita 'identidad'?". En Stuart Hall y Paul du Gay. (Comp.). Cuestiones de identidad cultural. Buenos Aires-Madrid: Amorrortu Editores. 
Informe reservado.net (21 de enero de 2007). "Sobre la ejecución de plan de viviendas en La Cava", Movimientos libres del sur: http:// libresdelsur.org.ar/archivo/?article645 [Consultado en marzo de 2012]

Ludmer, J. (2010). Aquí América Latina. Una especulación. Buenos Aires: Eterna Cadencia.

Martini, J. (2002). Puerto Apache. Buenos Aires: Editorial Sudamericana. Perlongher, N. (2008). Prosa Plebeya. Ensayos 1980-1992 (Selección y prólogo de Christian Ferrer y Osvaldo Baigorria). Buenos Aires: Colihue.

Ponce, N. (2004). Hijos nuestros. México: El Viejo Pozo.

Rama, A. (1995). La ciudad letrada. Montevideo: Arca.

Rosa, N. (1997). La lengua del ausente. Buenos Aires: Editorial Biblos.

Rosa, N. (2006). “La ficción proletaria”, La Biblioteca, no 4-5, pp. 32-51.

Saítta, S. (2006). "La narración de la pobreza en la literatura argentina del siglo veinte", Revista Nuestra América, no 2 (Agosto-Diciembre), pp. 89-102. 
